\title{
A comment on the equation of state and the freezing point equation with respect to subglacial lake modelling
}

\author{
Malte Thoma ${ }^{\mathrm{a}, \mathrm{b}}$ Klaus Grosfeld ${ }^{\mathrm{a}}$ Andrew M. Smith ${ }^{\mathrm{c}}$ \\ Christoph Mayer ${ }^{\mathrm{b}}$ \\ ${ }^{a}$ Alfred Wegener Institute for Polar and Marine Research, \\ Bussestrasse 24, 27570 Bremerhaven, Germany \\ ${ }^{\mathrm{b}}$ Bayerische Akademie der Wissenschaften, Kommission für Glaziologie, \\ Alfons-Goppel-Str. 11, 80539 München, Germany \\ c British Antarctic Survey, High Cross, Madingley Road, Cambridge, CB3 OET, \\ United Kingdom
}

\begin{abstract}
The empirical Equation of State (EoS) allows to calculate the density of water in dependence of salinity, temperature, and pressure. The three parameters have a complex interdependency on the EoS. Hence, whether warmer water parcels sink or raise depends on the surrounding salinity and pressure. The empirical Equation of Freezing Point (EoFP) allows to calculate the pressure and salinity dependent freezing point of water. Both equations are necessary to model the basal mass balance below Antarctic ice shelves or at the ice-water interface of subglacial lakes. This article aims three tasks: First we comment on the most common formulations of the EoS and the EoFP applied in numerical ocean and lake models during the past decades. Then we describe the impact of the recent and self-consistent Gibbs thermodynamic potential-formulation of the EOS and the EoFP on subglacial lake modeling. Finally, we show that the circulation regime of subglacial lakes covered by at least $3000 \mathrm{~m}$ of ice, in principle, is independent of the particular formulation, in contrast to lakes covered by a shallower ice sheet, like e.g., subglacial Lake Ellsworth. However, as modeled values like the basal mass balance or the distribution of accreted ice at the ice-lake interface are sensitive to different EoS and EoFP, we present updated values for subglacial Lake Vostok and subglacial Lake Concordia.
\end{abstract}

Key words: Subglacial Lakes, Equation of State, Freezing Point Equation, Numerical Modelling, Ice-ocean Interaction, Lake Vostok, Lake Concordia, Lake Ellsworth, Antarctica

Email address: Malte. Thoma@awi.de (Malte Thoma). 
25 Water flow within oceans and subglacial lakes is modelled by solving the hydro26 static primitive equations numerically (e.g., Haidvogel and Beckmann, 1999; 27 Griffies, 2004). These equations describe the flow of a fluid on the rotating 28 earth by the equation of motion, the conservation laws of temperature and 29 salinity, and an equation of state (EOS). Some fundamental differences be30 tween different models relate to the implementation of the vertical coordinate, which may be orientated planar, terrain-following, or along isopycnals. Well known representatives for these type of models are the Modular Ocean Model (MOM, e.g. Pacanowski and Griffies, 1998; Griffies et al., 2003), the Princeton Ocean Model (POM, e.g., Blumberg and Mellor, 1983; Ezer and Mellor, 2004), and the Miami Isopycnic Coordinate Ocean Model (MICOM, e.g., Bleck, 1998; Holland and Jenkins, 2001), respectively. Other approaches to solve the equations on unstructured grids apply spectral formulations (SEOM, e.g., Patera, 1984), finite volumes (MITgcm, e.g., Marshall et al., 1997a,b), or finite elements (COM, e.g., Danilov et al., 2004; Timmermann et al., 2009). The number of ocean models originating from these, in particular of those with structured horizontal grids, is high. However, each model has to implement the EoS. The empirical EoS is a complex nonlinear function to calculate the density as a function of temperature, salinity, and pressure $\rho=\rho(T, S, p)$. For the global ocean, it has to cover a wide parameter range in $S$ (0 to $42 \mathrm{psu}$ ), $T$ $\left(-2\right.$ to $\left.40^{\circ} \mathrm{C}\right)$, and $p(0$ to $100 \mathrm{MPa})$. Subglacial lakes range at the lower boundaries for $T$ and $S$ and the medium pressure range. In this parameter range, the slope of the calculated density is at its vertex, which has implications for the circulation and basal mass balance within subglacial lakes (Thoma et al., 2008b). Models that also include the interaction between ice and water, additionally apply an equation for the pressure-dependent freezing point of sea water $(\mathrm{EoFP}) T_{f}=T_{f}(S, p)$.

52 In the following we briefly review different representations of EOS and EoFP used in ocean modelling, before we discuss the relevance of their improved formulations for the modelling of subglacial lakes. Finally we present updated results of subglacial lake modelling studies, with respect to the revised EoS and EoFP.

\subsection{Equation of State (EoS)}

Early ocean models applied the Knudsen-Ekman equation, which relies on the Boussinesq approximation and linearises the EoS around some reference values for temperature, salinity and pressure (e.g., Fofonoff, 1962; Bryan and Cox, 1972). Although this approach reduces the computational effort significantly, 
it is only appropriate over very narrow ranges of $T$ and $S$. A more general approach is the so-called UNESCO-EoS (Fofonoff and Millard, 1983), derived from the fundamental work of Millero et al. (1980) and Millero and Poisson (1981). It consists of a set of 15 coefficients, to calculate the ocean's surface density $\rho_{0}(T, S)=\rho(T, S, p=0)$ and 26 subsequent coefficients for the secant bulk modulus $\kappa$ to evaluate the pressure dependence: $\rho(T, S, p)=$ $\rho_{0}(T, S) /(1-p / \kappa(T, S, p))$. This equation is valid over a large parameter range $-2^{\circ} \mathrm{C}<T<40^{\circ} \mathrm{C}, 0<S<42 \mathrm{psu}$, and $0<p<10^{8} \mathrm{~Pa}(\approx 10000 \mathrm{~m}$ depth $)$, and could hence be applied to the global ocean as a whole.

However, a complication arises from the fact, that the ocean models intrinsic variable is not the temperature $T$, but the potential temperature $\theta$, which excludes temperature changes induced by adiabatic processes. To bypass the time-consuming conversion of different temperature representations in ocean models, Jackett and McDougall (1995) published a modified set of coefficients for the UNESCO-formulation. This allows a straight calculation of the density from the potential temperature

$$
\rho(\theta, S, p)=\frac{\rho_{0}(\theta, S)}{1-p / \kappa(\theta, S, p)} .
$$

The pressure in (1) is calculated from integrating the hydrostatic equation

$$
\frac{\partial p}{\partial z}=-\rho g \quad \Rightarrow \quad p=g \int_{z}^{0} \rho(\theta, S, p) d z
$$

from the surface to the depth $z$. To improve efficiency in numerical ocean models solving (1) and (2) iteratively, either the density of a former model-timestep has to be used, or another set of coefficients for the UNESCO-formulation of the EoS has to be applied, which allows for a depth-dependent density calculation instead of pressure $\rho=\rho(\theta, S, z)$ (Haidvogel and Beckmann, 1999). However, this set of coefficients is based on a homogeneously stratified standard ocean and has significant limits as soon as deviations from this standard stratification arise. Figure 1 indicates the deviation of the Haidvogel and Beckmann (1999) formulation from the Jackett and McDougall (1995) formulation as soon as the temperature, salinity and/or depth diverges from the assumed reference values, which refer to the mean oceanic properties.

The most up-to-date approach for calculating the density of seawater depends on the Gibbs thermodynamic potential (e.g., Feistel, 1993; Feistel and Hagen, 1995; Feistel, 2003; Jackett et al., 2006). Thermodynamic properties, like density, freezing point, heat capacity, and many more, are calculated in a selfconsistent way by derivatives from this Gibbs potential. The improved density algorithm provided by Jackett et al. (2006) shows only minimal adjustments with respect to Jackett and McDougall (1995). However, because of the consistency of the derived thermodynamic properties and the significantly reduced 

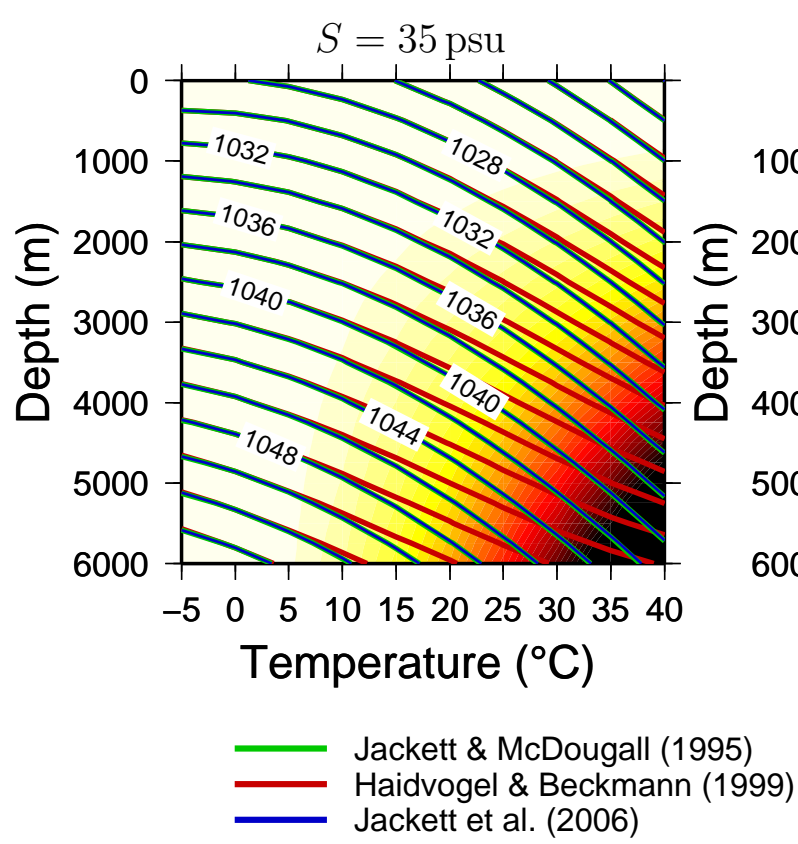
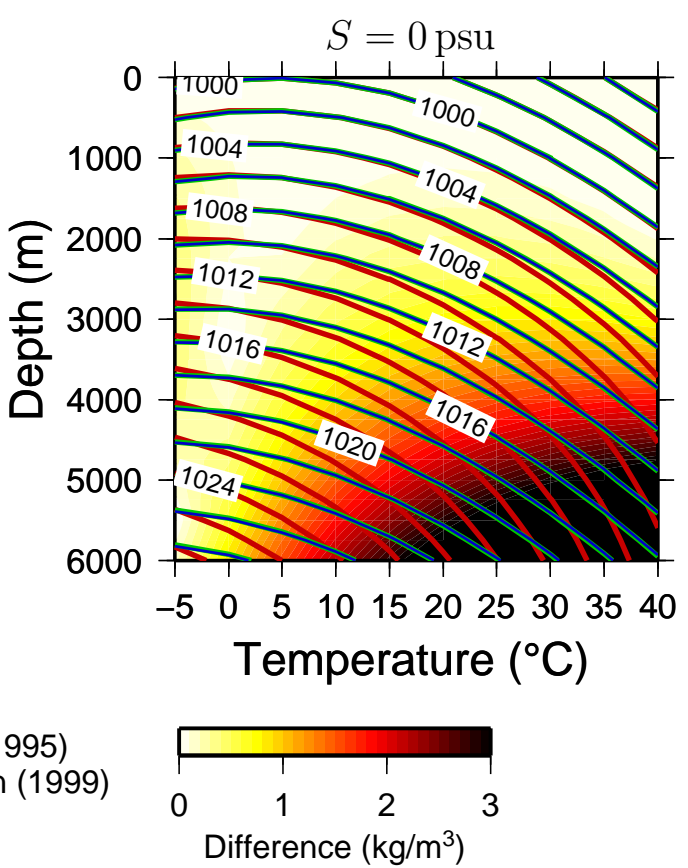

Fig. 1. Density $\left(\mathrm{kg} / \mathrm{m}^{3}\right)$ as a function of depth and potential temperature for oceanic water masses (left) and fresh water (right). The blue and green lines, which are quite close together, refer to Jackett and McDougall (1995) and Jackett et al. (2006), respectively, while the red lines refers to Haidvogel and Beckmann (1999). The background color indicates the increasing difference between the pressureand depth-dependent density according to Jackett and McDougall (1995) and Haidvogel and Beckmann (1999).

computational effort, the implementation of the Gibbs-potential algorithms in ocean models is the preferred formulation.

\subsection{Equation of freezing point (EoFP)}

For an adequate treatment of the ice-water interaction the equations for the conservation of temperature and salinity are complemented by an equation to calculate the pressure- and salinity-dependent freezing point of water (EoFP, e.g., Holland and Jenkins, 1999)

$$
T_{f}=T_{f}(S, p) \approx \alpha S+\beta+\gamma p,
$$

where $\alpha=0.057^{\circ} \mathrm{C} / \mathrm{psu}, \beta=0.0939^{\circ} \mathrm{C}$, and $\gamma=7.64 \cdot 10^{-4}{ }^{\circ} \mathrm{C} / \mathrm{dbar}$. For an analytic solution of the complete set of the three equations a linearized version of the EoFP is needed as indicated on the right hand side of (3). This set of coefficients dating back to Foldvik and Kvinge (1974) is still in use in models dealing with ice-water interaction and has not always been replaced by a linearised version of the more precise (but higher order) formulation of Fofonoff and Millard (1983). One drawback of (3) is the need for regular 
temperature conversions between $T$ and the models intrinsic variable $\theta$. Also, the EoFP (3) was not designed for the high-pressure, low-salinity environment within subglacial lakes, which are covered by several thousand meters of ice (Feistel, 2003, 2008). Jackett et al. (2006) present an algorithm to calculate the freezing point in terms of the potential temperature $\theta_{f}=\theta_{f}(S, p)$, based on the Gibbs-potential considerations of Feistel (2003). This formulation of the EoFP is also valid for high-pressure environments found in subglacial lakes. To make this formulation applicable with the analytic solution of the three-equation formulation, it has to be linearised with respect to the specific environmental needs ( $S \sim$ mean-salinity-at-ice-water-interface, $p \sim$ mean-interface-depth). For subglacial Lake Vostok (with $S=0 \mathrm{psu}$ and $p \approx 3700 \mathrm{~m}$ ) the adjusted linearized equation (3) is indicated by the red line in Figure 2, while the original freezing point line (according to Jackett et al., 2006) is drawn in black.

\section{Relevance for subglacial lake modelling}

In former studies of subglacial lake circulation, different formulations of the EoS have been applied. In the first three-dimensional numerical model studies of Lake Vostok, the simplistic Knudsen-Ekman equation was used (Williams, 2001; Mayer et al., 2003). Later studies dealing with Lake Vostok and Lake Concordia (Thoma et al., 2007, 2008a,b, 2009) applied the improved depthdependent EoS after Haidvogel and Beckmann (1999). However, Figure 1 indicates that in the fresh-water regime of subglacial lakes the application of this convenient approach is questionable. Although the absolute densities are quite similar (Figure 1), the different vertical gradient and in particular the resulting significantly different isopycnal-vertices determine the characteristics of flow and basal mass balance within subglacial lakes. The line of maximum density (LoMD) connects the vertices of the isopycnals, indicated as a dashed line in Figure 2. The LoMD determines if warming leads to rising of water masses or sinking. By using the improved Gibbs-potential formulation, the LOMD is moved to a greater depth compared to the Haidvogel and Beckmann (1999) approach. However, as long as the a lake's depth below the ice surface remains well below the LoMD in Figure 2, the principle circulation regime doesn't change (Thoma et al., 2008b).

\section{Updated subglacial lake model results}

The most up-to date model to simulate the three-dimensional flow regime and the basal mass balance within subglacial lakes is Rombax (Thoma et al., 2007, 


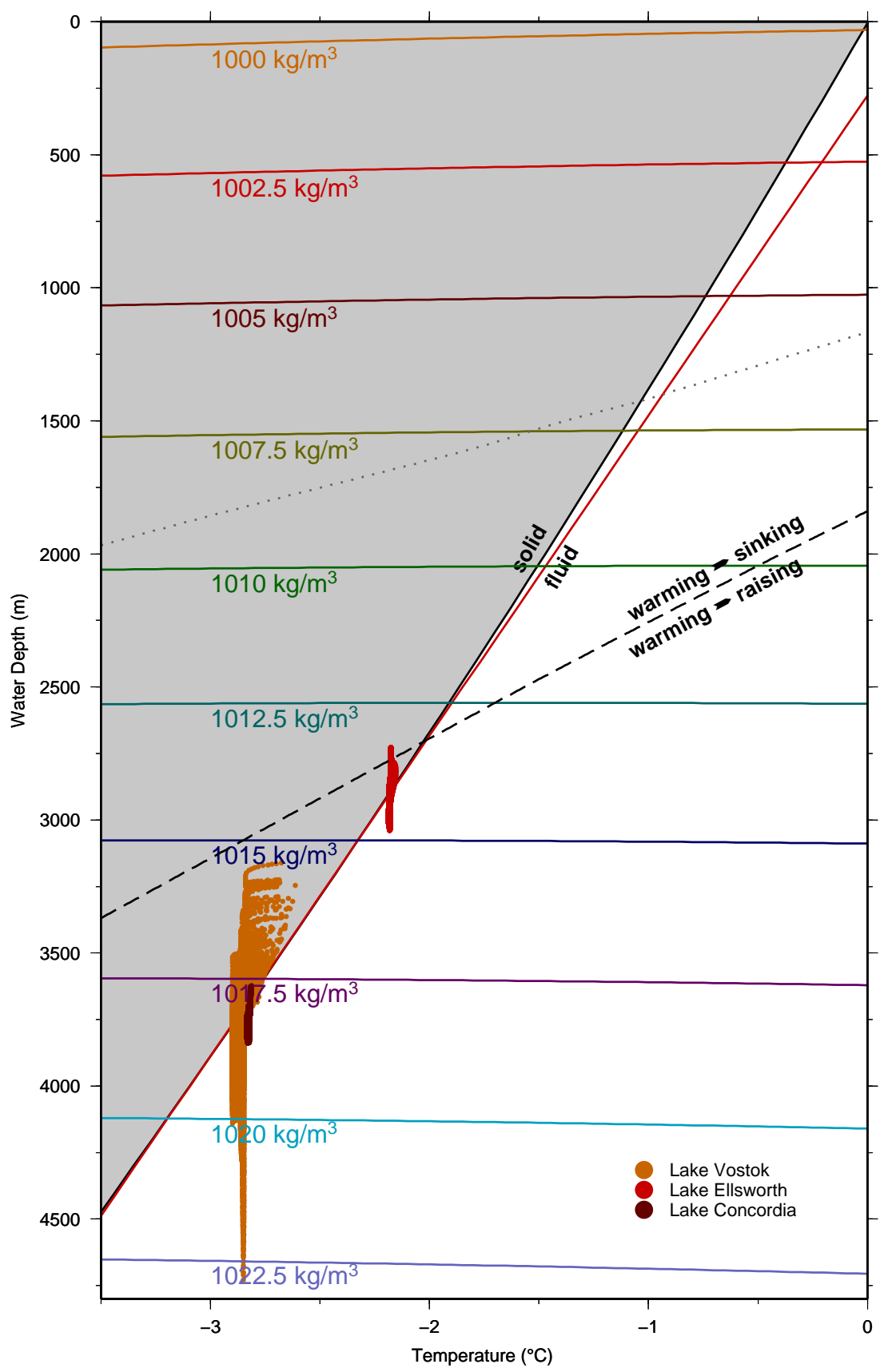

Fig. 2. Water depth and potential temperature dependence of isopycnals (Feistel, 2003; Jackett et al., 2006). The black solidus line shows the depth-dependent freezing point of fresh water (Feistel, 2003; Jackett et al., 2006), the red solidus line indicates the linearized form of the freezing point equation adjusted for Lake Vostok. The dashed line connects the isopycnal's vertices and indicates the line of maximum density (LOMD). The dotted gray line indicates the former LOMD according to Haidvogel and Beckmann (1999) as published in Thoma et al. (2008b). Coloured dots show the captured space of potential temperatures and equivalent water depth for Lake Vostok, Lake Concordia, and Lake Ellsworth, respectively. Dots within the grey shaded area above the solidus line represent supercooled water masses with freezing capability. 
2008a,b, 2009). In order to investigate the impact of the improved formulations of the EoS and the EoFP, we repeated the most important model runs of our former studies and reanalyse the results. The model set-up for Lake Vostok uses the bathymetry model of Filina et al. (2008). The corresponding boundary conditions are described in detail in Thoma et al. (2007, 2008a,b). In addition to the previously applied geothermal heat flux of $54 \mathrm{~mW} / \mathrm{m}^{2}$ Maule et al. (2005), which is based on the interpretation of satellite magnetic data, we also apply a value of $48 \mathrm{~mW} / \mathrm{m}^{2}$, from the interpretation of seismic data (Shapiro and Ritzwoller, 2004). This allows us to estimate an uncertainty for Lake Vostok, with respect to this parameter, as specified in Table 1.

The model set-up for Lake Concordia is fully described in Thoma et al. (2009). Here we only present the updated results with respect to the revised EOS and EoFP with otherwise identical configurations. Since Lake Vostok and Lake Concordia are still located well below the line of maximum density (LoMD, Figure 2), no fundamental regime shifts are observed. However, the absolute values of the modelled flow, the basal mass balance, as well as the derived distributions of the accreted ice at the ice-lake interface, and the lake water residence times do change slightly. In Table 1 we present updates of the most relevant results and their uncertainties for Lake Vostok and Lake Concordia published in the aforementioned studies. A complete set of Figures indicating the circulation, temperature regime, basal mass balance, and the distribution and thickness of accreted ice for Lake Vostok and for Lake Concordia is presented in the supplemental material.

\section{Summary and implications for future subglacial lake studies}

The general circulation regime within subglacial lakes is generated by buoyancy forces, originating from the geothermal heat flux and the thermodynamic interactions at the ice-lake interface. However, the specific flow as well as the basal mass balance of any lake is determined by its complex bathymetry and the steepness of the ice-lake interface slope. This makes reliable generalized predictions of any specific values for an individual lake impossible; each lake must be considered individually.

The buoyancy force, which drives the flow within subglacial lakes, depends very much on the EoS. According to Wüest and Carmack (2000) and Thoma et al. (2008b), a fundamental regime shift is observed when the LOMD is approached or crossed. With respect to this, the previous results on subglacial Lake Vostok and subglacial Lake Concordia do not change in their general aspects, but in their specific quantities. In contrast, the recently investigated Lake Ellsworth (Woodward et al., 2009) provides a rather different situation Compared to many other subglacial lakes, Lake Ellsworth is covered by a 
Table 1

Revised values for important modelled results within subglacial lakes with respect to improved versions of the EoS and the EoFP. The uncertainties are derived from model runs with varying boundary conditions.

\begin{tabular}{llcc}
\hline & & Lake Vostok & Lake Concordia \\
\hline Min. stream func. & $(\mathrm{mSv})$ & $-11.6 \pm 0.1$ & $-0.10 \pm 0.01$ \\
Max. stream func. & $(\mathrm{mSv})$ & $+22.5 \pm 0.1$ & $+0.11 \pm 0.01$ \\
Merid. overturning & $(\mu \mathrm{Sv})$ & $( \pm 1.8 \pm 0.1) \cdot 10^{3}$ & $-14.7 \pm 0.1$ \\
Zonal overturning & $(\mu \mathrm{Sv})$ & $(-11.6 \pm 0.1) \cdot 10^{3}$ & $+55.6 \pm 0.4$ \\
Velocity (horizontal) & $(\mathrm{mm} / \mathrm{s})$ & $\mathcal{O} 1$ & $\mathcal{O}$ \\
$\quad(\mu \mathrm{m} / \mathrm{s})$ & $\mathcal{O} 10$ & $\mathcal{O} 1$ \\
$\quad\left(10^{-2} \mathrm{~cm}^{2} / \mathrm{s}^{2}\right)$ & $1.9 \pm 0.1$ & $(3.52 \pm 0.05) \cdot 10^{-2}$ \\
Turb. kin. energy & $\left.(\mathrm{km})^{2}\right)$ & $5212 \pm 85$ & $115 \pm 55$ \\
Freezing area & $(\mathrm{mm} / \mathrm{a})$ & $16.8 \pm 0.3$ & $3.8 \pm 1.2$ \\
Mean melt rate & $(\mathrm{mm} / \mathrm{a})$ & $24.7 \pm 0.3$ & $1.3 \pm 0.2$ \\
Mean freeze rate & $\left(10^{-1} \mathrm{~m}^{3} / \mathrm{s}\right)$ & $15.7 \pm 1.6$ & $0.57 \pm 0.27$ \\
Fresh water gain & $\left(10^{-2} \mathrm{~km}^{3} / \mathrm{a}\right)$ & $5.0 \pm 0.5$ & $0.18 \pm 0.09$ \\
Basal ice loss & $\left(\mathrm{km}^{2}\right)$ & $11000 \pm 500$ & $125 \pm 55$ \\
Accreted ice area & $\left(\mathrm{km}^{3}\right)$ & $855 \pm 20$ & $2.0 \pm 1.6$ \\
\multicolumn{1}{c}{ volume } & $(\mathrm{m})$ & $70 \pm 10$ & $12 \pm 7$ \\
\multicolumn{1}{c}{ average thickness } & $17.0 \pm 0.4$ & $3.8 \pm 1.1$ \\
Melting rate in meteoric area & $(\mathrm{mm} / \mathrm{a})$ & $51.7 \pm 5.6$ & $18.9 \pm 7.4$ \\
Lake water residence time & $\left(\mathrm{ka}^{2}\right.$ & & \\
\hline
\end{tabular}

thinner ice sheet, moving it towards the LoMD (Figure 2). Additionally, the slope of the ice-lake interface is significantly larger (about 1.9\%) compared to Lake Vostok or Lake Concordia (about 0.4\%), which will have its impact on the basal mass balance. A future detailed modelling study of subglacial Lake Ellsworth will show this in detail.

Acknowledgements: This work was funded by the DFG through grant MA33471-2. The authors wish to thank Aike Beckmann, Rainer Feistel, Rüdiger Gerdes, Kate Hedstrom, Adrian Jenkins, Martin Losch, Trevor McDougall, and Ralph Timmermann for helpful comments and discussions.

\section{References}

Bleck, R., 1998. Ocean modeling in isopycnic coordinates. In: Chassignet, E. P., Verron, J. (Eds.), Ocean Modeling and Parameterization. Vol. 516. NATO ASI Mathematical and Physical Sciences Series, Kluwer, pp. 423448.

Blumberg, A. F., Mellor, G. L., 1983. Diagnostic and prognostic numerical circulation studies of the South Atlantic Bight. J. Geophys. Res. 88. 
Bryan, K., Cox, M. D., 1972. An approximate equation of state for numerical models of ocean circulation. J. Phys. Oceanogr. 2, 510-514.

Danilov, S., Kivman, G., Schröter, J., 2004. A finite-element ocean model: principles and evaluation. Ocean Modelling 6 (2), 125-150.

Ezer, T., Mellor, G. L., 2004. A generalized coordinate ocean model and a comparison of the bottom boundary layer dynamics in terrain-following and in z-level grids. Ocean Modelling 6, 379-403.

Feistel, R., 1993. Equilibrium thermodynamics of seawater revisited. Progress In Oceanography 31, 101-179, doi: 10.1016/0079-6611(93)90024-8.

Feistel, R., 2003. A new extended gibbs thermodynamic potential of seawater. Progress In Oceanography 58, 43-114, doi: 10.1016/S0079-6611(03)00088-0.

Feistel, R., 2008. A Gibbs function for seawater thermodynamics for -6 to $80{ }^{\circ} \mathrm{C}$ and salinity up to $120 \mathrm{~g} \mathrm{~kg}^{-1}$. Deep-Sea Res. 55, 1639-1671, doi: 10.1016/j.dsr.2008.07.004.

Feistel, R., Hagen, E., 1995. On the GIBBS thermodynamic potential of seawater. Progress In Oceanography 36, 249-327, doi: 10.1016/00796611(96)00001-8.

Filina, I. Y., Blankenship, D. D., Thoma, M., Lukin, V. V., Masolov, V. N., Sen, M. K., 2008. New 3D bathymetry and sediment distribution in Lake Vostok: Implication for pre-glacial origin and numerical modeling of the internal processes within the lake. Earth Pla. Sci. Let. 276, 106-114, doi:10.1016/j.epsl.2008.09.012.

Fofonoff, N. P., 1962. Physical properties of sea-water. In: Hill, M. N. (Ed.), The Sea. Vol. 1. Interscience Publ., pp. 3-30.

Fofonoff, N. P., Millard, R. C., 1983. Algorithms for computation of fundamental properties of seawater. UNESCO Technical papers in marine science $44,29$.

Foldvik, A., Kvinge, T., 1974. Conditional instability of sea water at the freezing point. Deep-Sea Res. 21, 169-197.

Griffies, S. M., 2004. Fundamentals of ocean climate models. Princeton University Press, Princeton.

Griffies, S. M., Harrison, M. J. Pacanowski, R. C., Rosati, A., 2003. A Technical Guide to MOM4. NOAA/Geophysical Fluid Dynamics Laboratory, Princton.

Haidvogel, D. B., Beckmann, A., 1999. Numerical ocean circulation modeling. Imperial Collage Press, London.

Holland, M. D., Jenkins, A., 1999. Modeling thermodynamic ice-ocean interaction at the base of an ice shelf. J. Phys. Oceanogr. 29, 1787-1800.

Holland, M. D., Jenkins, A., 2001. Adaptation of an isopycnic coordinate ocean model for the study of circulation beneath ice shelves. Mon. Wea. Rev. 129, 1905-1927.

Jackett, D. R., McDougall, T. J., 1995. Minimal adjustment of hydrographic profiles to achieve static stability. J. Atmos. Ocean. Technol. 12, 381-389.

Jackett, D. R., McDougall, T. J., Feistel, R., Wright, D. G., Griffies, S. M., 2006. Algorithms for density, potential temperature, conservative tempera- 
ture, and the freezing temperature of seawater. J. Atmos. Ocean. Technol. 23, 1709-1728, doi: 10.1175\%2FJTECH1946.1.

Marshall, J., Adcroft, A., Hill, C., Perelman, L., Heisey, C., 1997a. A finitevolume, incompressible navier stokes model for studies of the ocean on parallel computers. J. Geophys. Res. 102 (C3), 5753-5766.

Marshall, J., Hill, C., Perelman, L., Adcroft, A., 1997b. Hydrostatic, quasihydrostatic, and nonhydrostatic ocean modeling. J. Geophys. Res. 102 (C3), 5733-5752.

Maule, C. F., Purucker, M. E., Olsen, N., Mosegaard, K., Jul. 2005. Heat Flux Anomalies in Antarctica Revealed by Satellite Magnetic Data. Science 309, 464-467, doi: 10.1126/science.1106888.

Mayer, C., Grosfeld, K., Siegert, M., 2003. Salinity impact on water flow and lake ice in Lake Vostok, Antarctica. Geophys. Res. Lett. 30 (14), 1767, doi:10.1029/2003GL017380.

Millero, F. J., Chen, C.-T., Bradshaw, A., Schleicher, K., 1980. A new high pressure equation of state for seawater. Deep-Sea Res. 27 (3-4), 255-264.

Millero, F. J., Poisson, A., 1981. International one-atmosphere equation of state of seawater. Deep-Sea Res. 28 (6), 625-629.

Pacanowski, R. C., Griffies, S. M., 1998. MOM 3.0 Manual. NOAA/Geophysical Fluid Dynamics Laboratory, Princton.

Patera, A. T., 1984. A spectral element method for fluid dynamics: Laminar flow in a channel expansion". J. Comp. Phys. 54 (3), 468-488.

Shapiro, N. M. S., Ritzwoller, M. H., 2004. Inferring surface heat flux distributions guided by a global seismic model: particular application to Antarctica. Earth Pla. Sci. Let. 223 (1-2), 213-224.

Thoma, M., Filina, I., Grosfeld, K., Mayer, C., 2009. Modelling flow and accreted ice in subglacial Lake Concordia, Antarctica. Earth Pla. Sci. Let. $286(1-2), 278-284$.

Thoma, M., Grosfeld, K., Mayer, C., Dec. 2007. Modelling mixing and circulation in subglacial Lake Vostok, Antarctica. Ocean Dynamics 57 (6), 531-540, doi: 10.1007/s10236-007-0110-9.

Thoma, M., Grosfeld, K., Mayer, C., 2008a. Modelling accreted ice in subglacial Lake Vostok, Antarctica. Geophys. Res. Lett. 35 (L11504), 1-6, doi:10.1029/2008GL033607.

Thoma, M., Mayer, C., Grosfeld, K., 2008b. Sensitivity of Lake Vostok's flow regime on environmental parameters. Earth Pla. Sci. Let. 269 (1-2), 242247, doi:10.1016/j.epsl.2008.02.023.

Timmermann, R., Danilov, S., Schröter, J., Böning, C., Sidorenko, D., Rollenhagen, K., 2009. Ocean circulation and sea ice distribution in a finite element global sea ice-ocean model. Ocean Modelling 27 (3-4), 114-129.

Williams, M. J. M., 2001. Application of a three-dimensional numerical model to Lake Vostok: An Antarctic subglacial lake. Geophys. Res. Lett. 28 (3), $531-534$.

Woodward, J., Smith, A. M., Ross, N., Thoma, M., Siegert, M. J., King, M. A., Corr, H. F. J., King, E. C., Grosfeld, K., 2009. Bathymetry of Subglacial 
Lake Ellsworth, West Antarctica and implications for lake access. Geophys.

282 Res. Lett. in preparation.

${ }_{283}$ Wüest, A., Carmack, E., 2000. A priori estimates of mixing and circulation

${ }_{284}$ in the hard-to-reach water body of Lake Vostok. Ocean Modelling 2 (1), $29-43$. 


\title{
Supplemental material for A comment on the equation of state and the freezing point equation with respect to subglacial lake modelling
}

\author{
${ }_{5} \quad$ Malte Thoma ${ }^{\mathrm{a}, \mathrm{b}}$ Klaus Grosfeld ${ }^{\mathrm{a}}$ Andrew M. Smith ${ }^{\mathrm{c}}$ \\ Christoph Mayer ${ }^{b}$ \\ a Alfred Wegener Institute for Polar and Marine Research, \\ Bussestrasse 24, 27570 Bremerhaven, Germany \\ ${ }^{\mathrm{b}}$ Bayerische Akademie der Wissenschaften, Kommission für Glaziologie, \\ Alfons-Goppel-Str. 11, 80539 München, Germany \\ c British Antarctic Survey, High Cross, Madingley Road, Cambridge, CB3 0ET, \\ United Kingdom
}

\section{$3 \quad 1$ Introduction}

The application of the Gibbs thermodynamic potential for the formulation of the Equation of State (EoS) and the Freezing Point Equation (EoFP) enables a consistent description for their application to ocean and/or subglacial lake flow models. As already discussed in the corresponding article, the general pattern of subglacial lake circulation, melting and freezing, and the thermal regime remains unchanged, but their quantitative structure adapts to the new formulations. While these revised quantities are published in the corresponding paper, we supply a new set of figures for subglacial Lake Vostok as well as for subglacial Lake Concordia in order to update the results shown in Thoma et al. (2007), Thoma et al. (2008b), Thoma et al. (2008a), and Thoma et al. (2009).

Email address: Malte. Thoma@awi.de (Malte Thoma). 
26 For the figures in this section the most up-to date bathymetry model of ${ }_{27}$ Filina et al. (2008) as well as a geothermal heat flux of $48 \mathrm{~mW} / \mathrm{m}^{2}$ is applied. 28 All other model parameters as well as boundary conditions are fully described 29 in the corresponding publications.
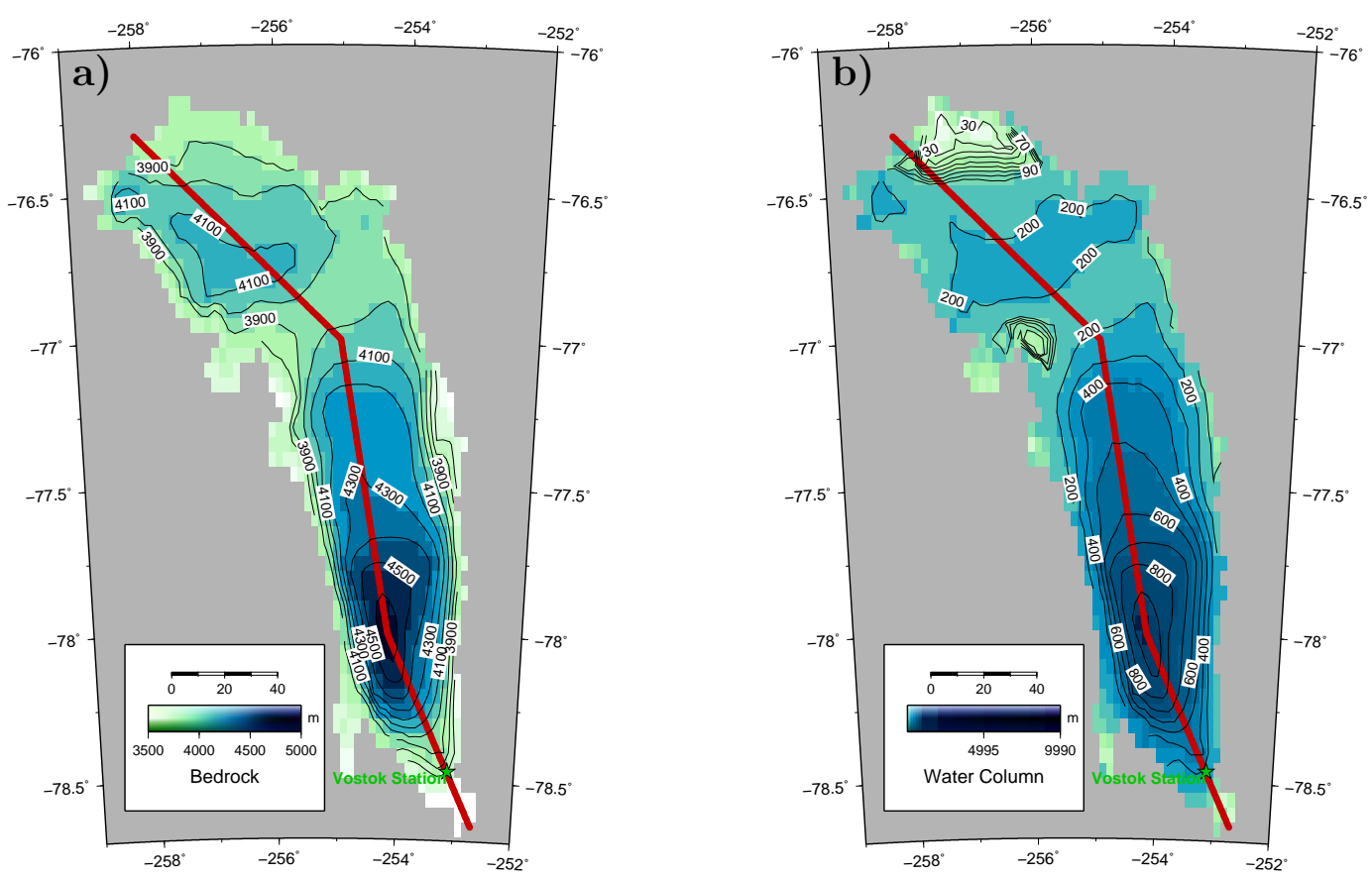

Fig. 1. Bedrock topography (a) and water column thickness (b) of Lake Vostok. The solid red line indicates the track along the cross sections shown in Figures 4b. 

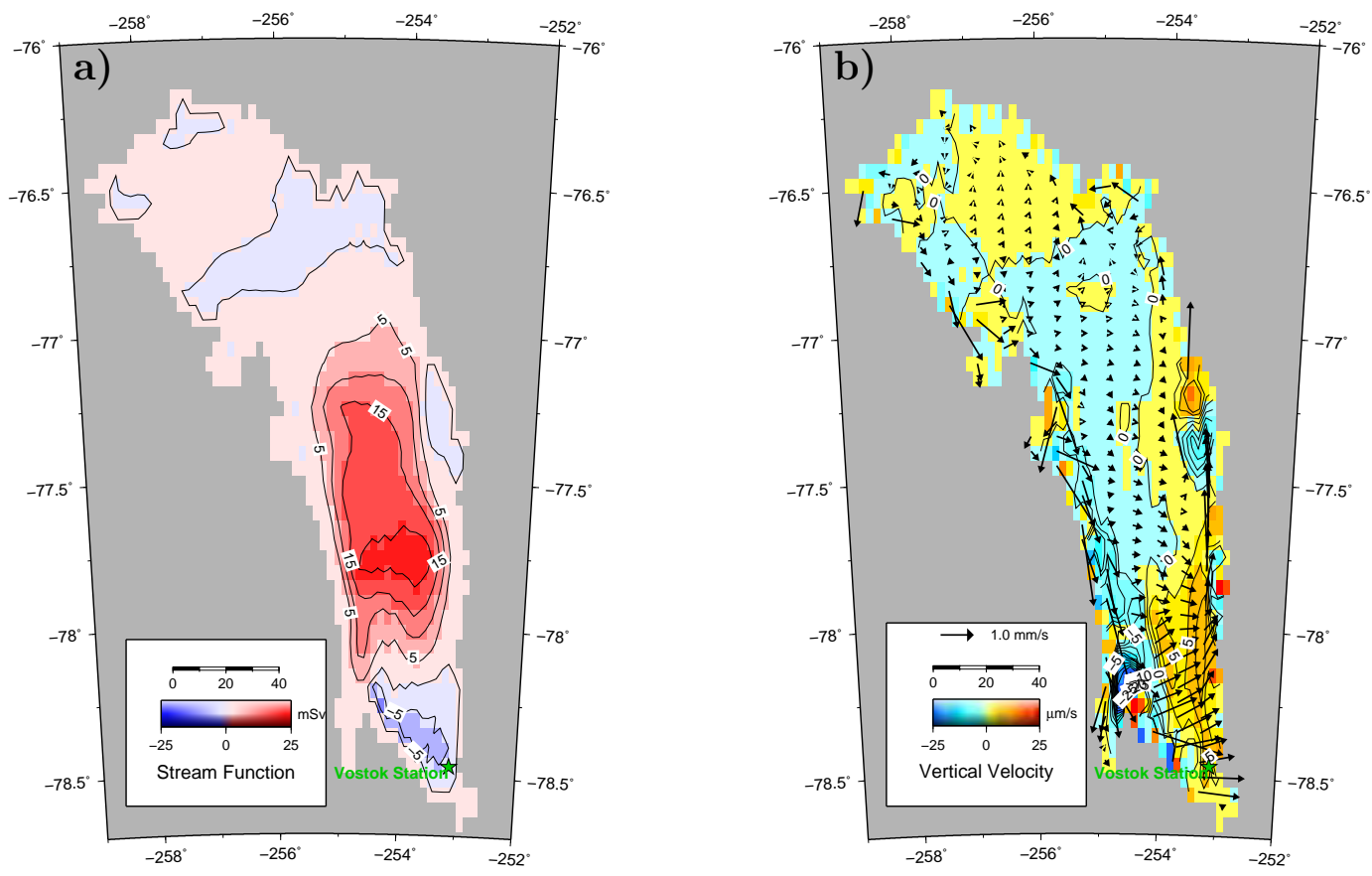

Fig. 2. a) Vertically integrated mass transport stream function $\left(1 \mathrm{mSv}=10^{3} \mathrm{~m}^{3} / \mathrm{s}\right)$. b) Integrated vertical velocity, arrows indicate the flow in the lake's bottom layer.
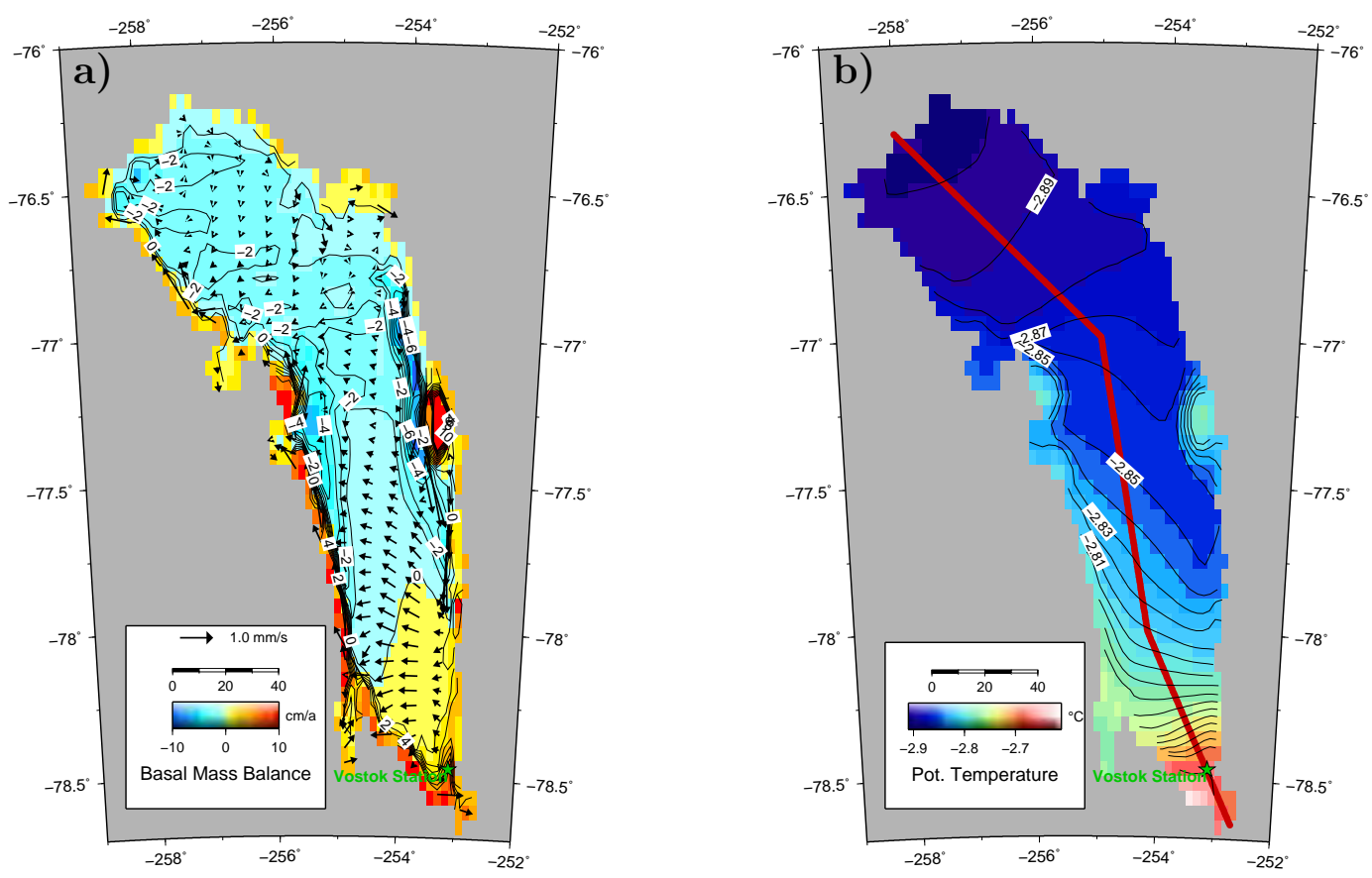

Fig. 3. a) Modelled basal mass balance at the ice-lake interface. Negative values (blue/green) indicate melting, positive (yellow/red) values freezing. Velocities in the ice-lake boundary layer are indicated by arrows. b) Modelled temperatures at the ice-lake interface. The solid red line indicates the track along the cross sections shown in Figures 4b. 

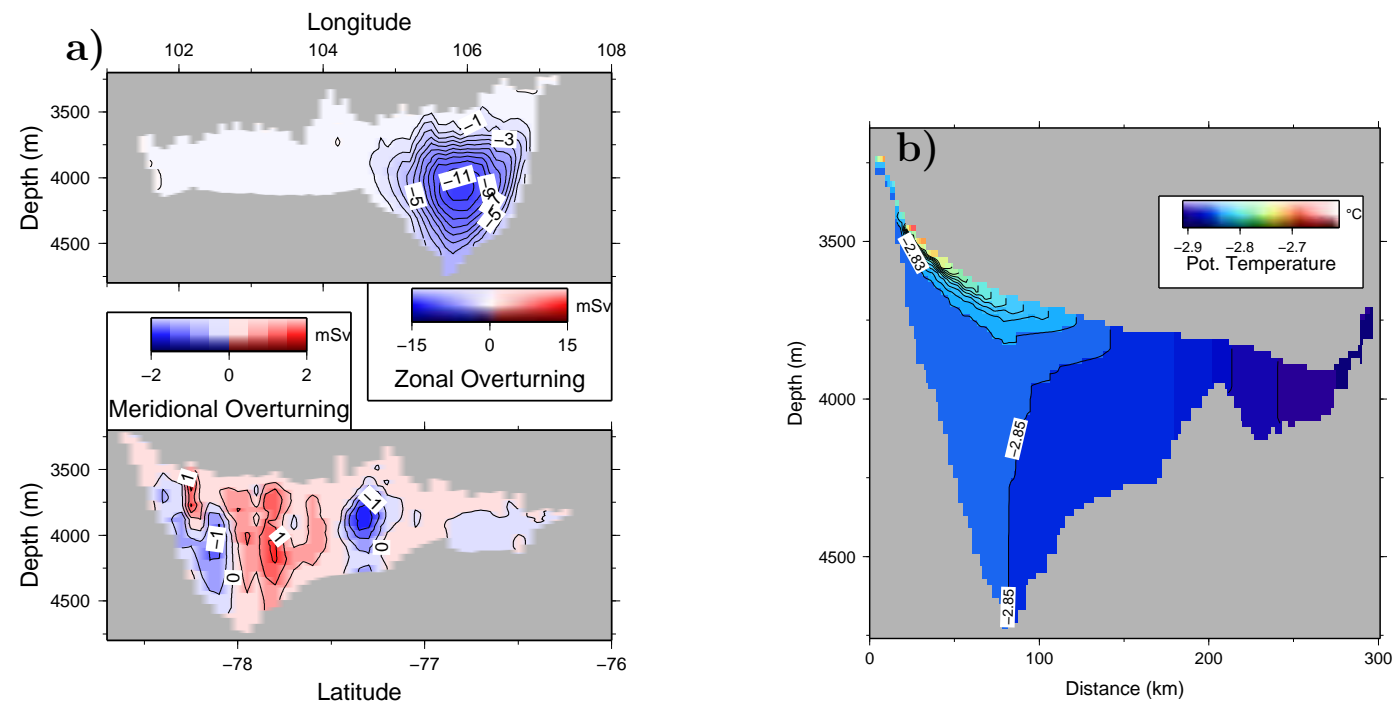

Fig. 4. a) Zonal and meridional overturning stream functions $\left(1 \mathrm{mSv}=10^{3} \mathrm{~m}^{3} / \mathrm{s}\right)$. b) South-north temperature cross section across Lake Vostok along the track indicated in Figure 1 and 3b.

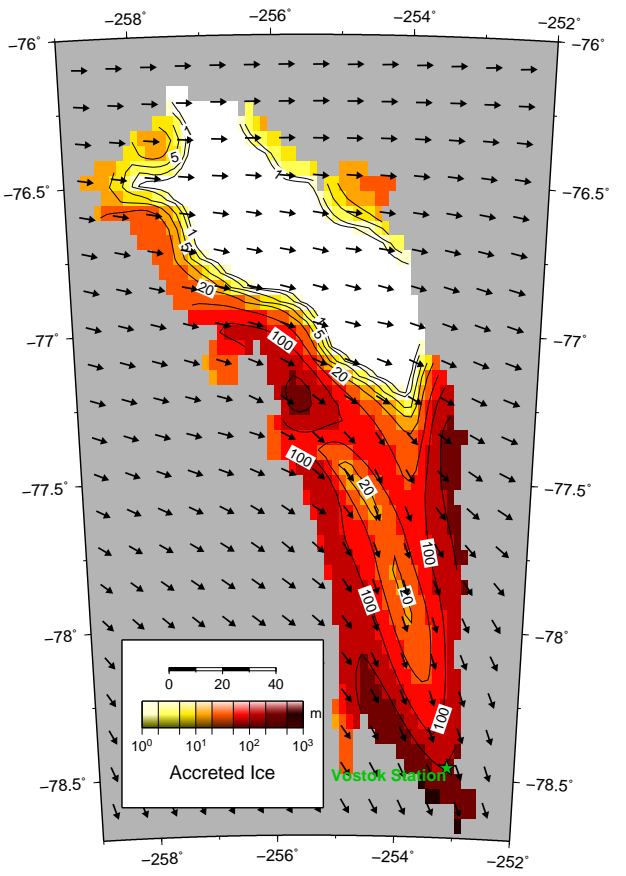

Fig. 5. Modelled accreted ice thickness (in meter) at the ice-lake interface The corresponding ice flow direction is indicated. The horizontal flow velocity is assumed to be $3.7 \mathrm{~m} / \mathrm{a}$, which results in $210 \mathrm{~m}$ of accreted ice, as measured at Vostok Station. This value is within the proposed measured velocities of about 1.9 and $4.2 \mathrm{~m} / \mathrm{a}$ (e.g., Kwok et al., 2000; Bell et al., 2002; Tikku et al., 2004; Wendt, 2005). 
31 For the model output in this section the bathymetry model presented in 32 Thoma et al. (2009) as well as a geothermal heat flux of $57 \mathrm{~mW} / \mathrm{m}^{2}$ (Maule et al., 33 2005; Tikku et al., 2005) and a heat flux into the ice sheet of $28.6 \mathrm{~mW} / \mathrm{m}^{2}$ 34 (Thoma et al., 2009) is applied.
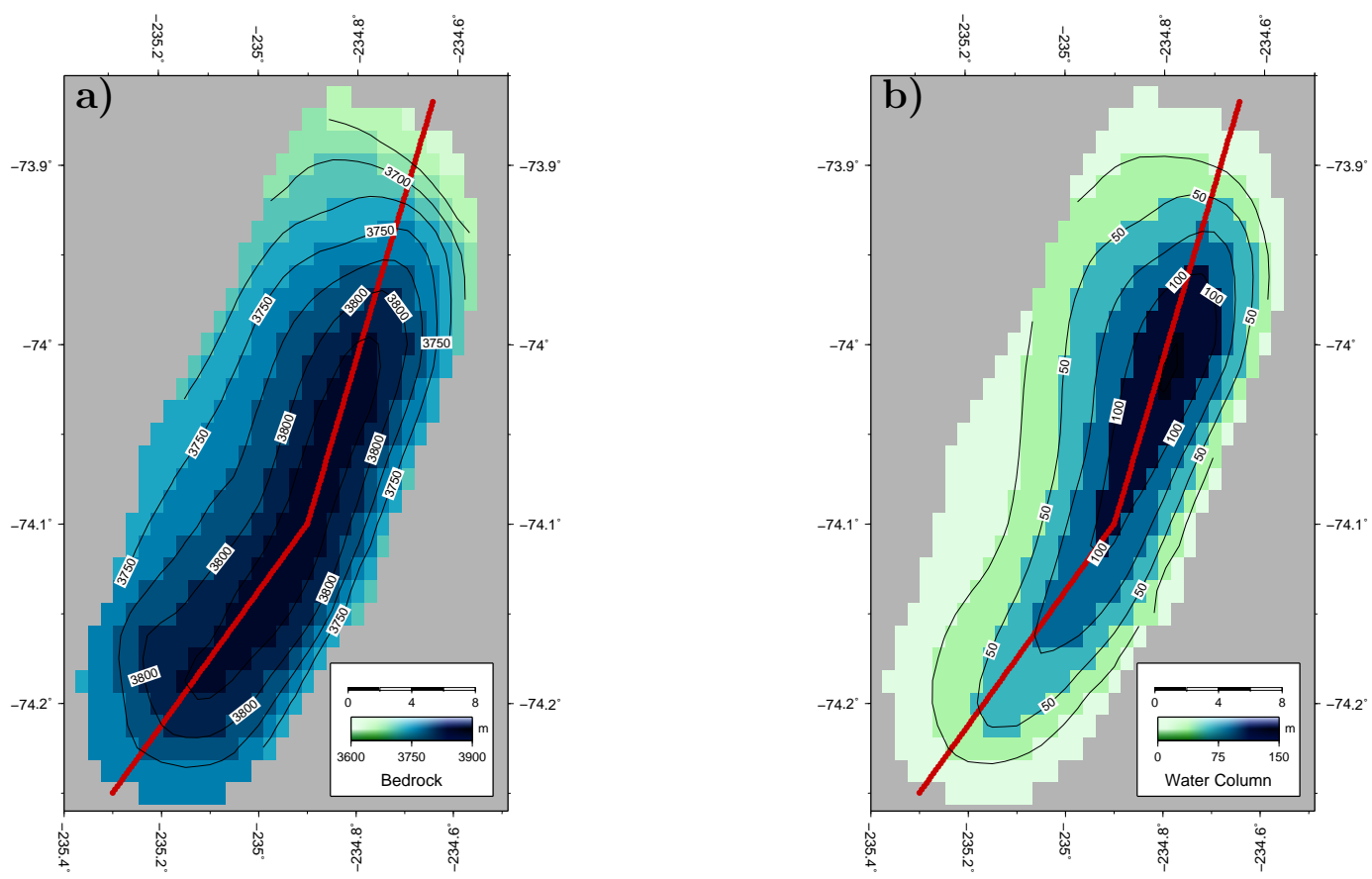

Fig. 6. Bedrock topography (a) and water column thickness (b) of Lake Concordia. The solid red line indicates the track along the cross sections shown in Figures $9 \mathrm{~b}$. 

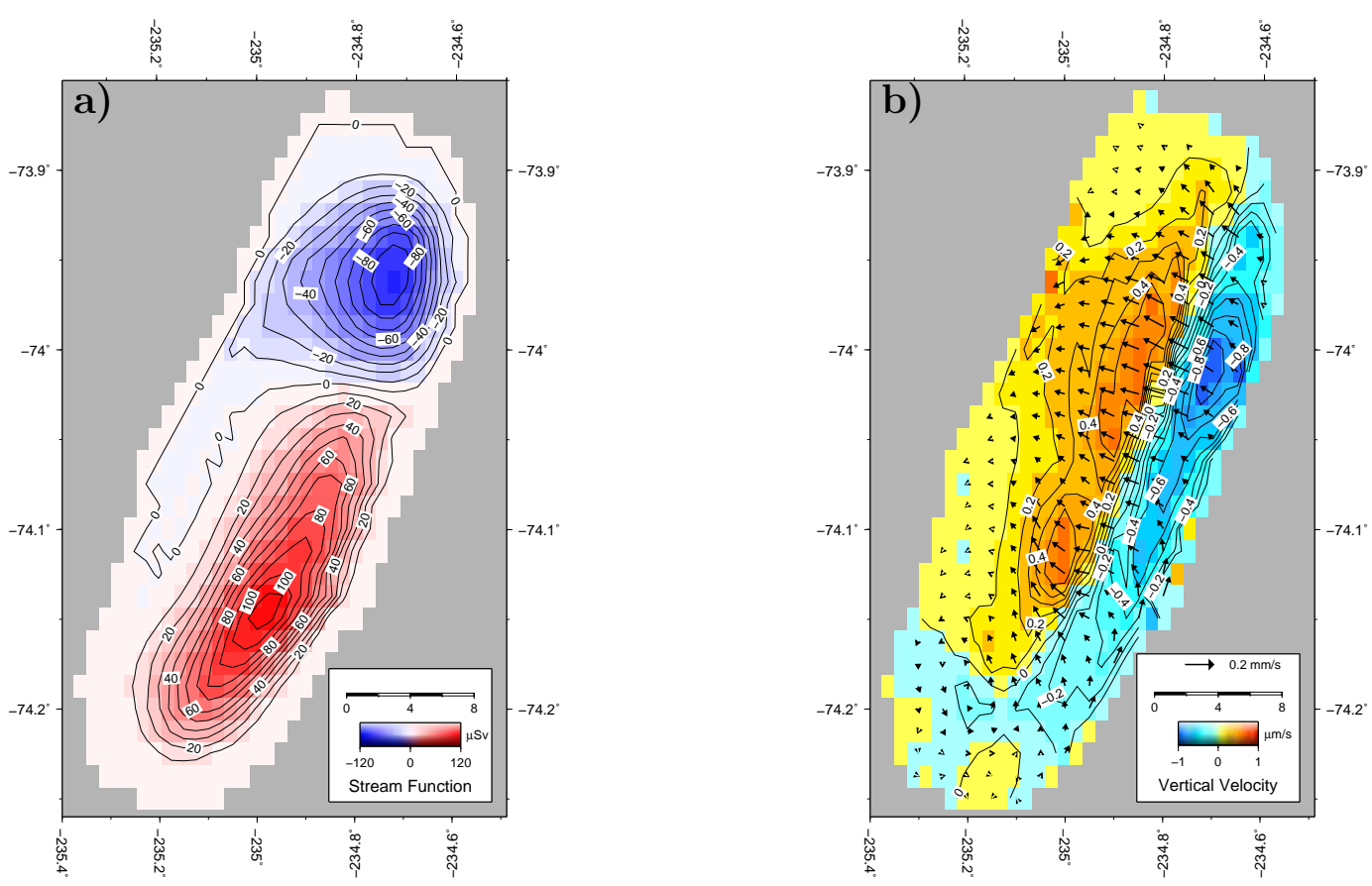

Fig. 7. a) Vertically integrated mass transport stream function $\left(1 \mathrm{~Sv}=10 \mathrm{~m}^{3} / \mathrm{s}\right)$. b) Integrated vertical velocity, arrows indicate the flow in the lake's bottom layer.
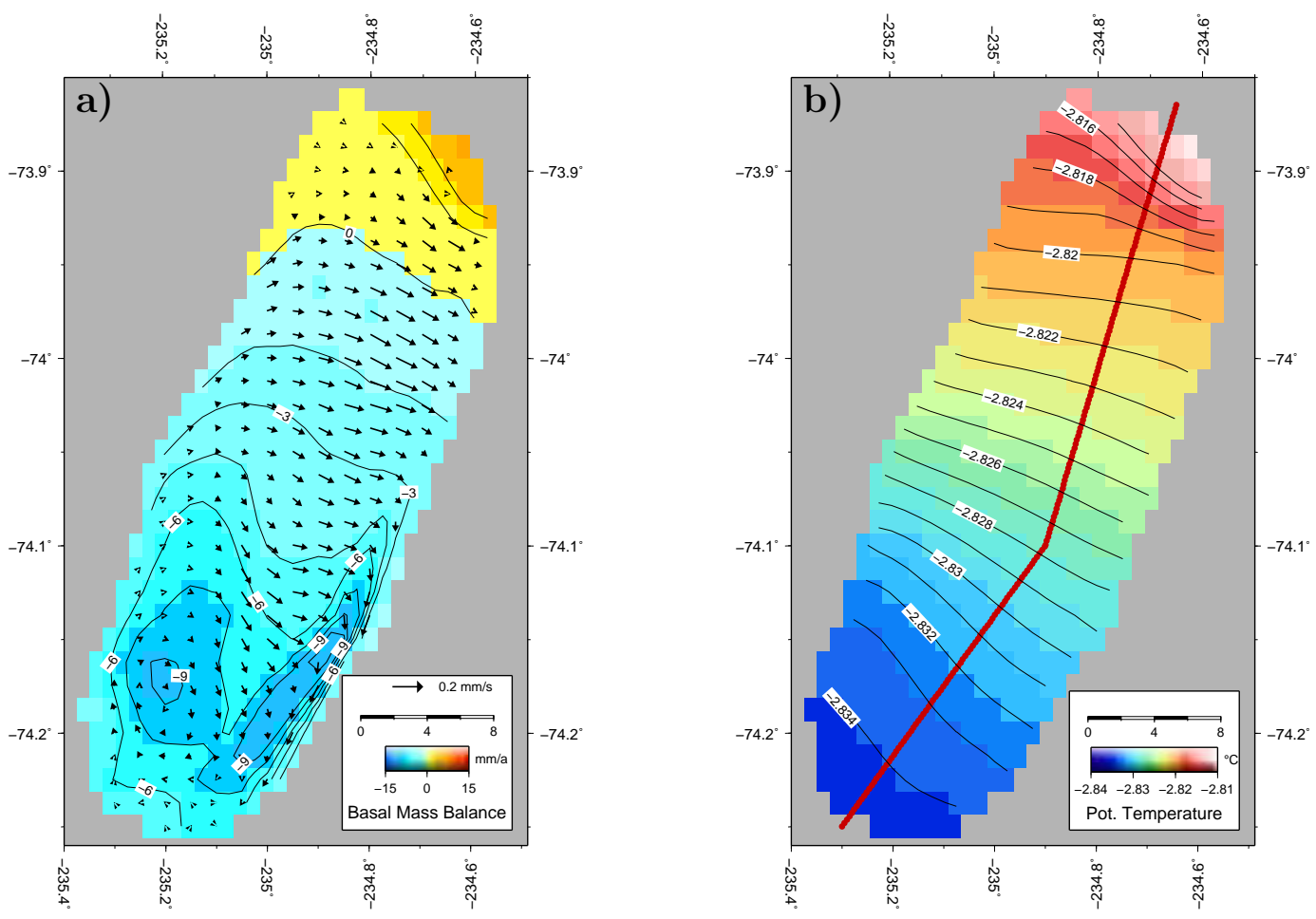

Fig. 8. a) Modelled basal mass balance at the ice-lake interface. Negative values (blue/green) indicate melting, positive (yellow/red) values freezing. Velocities in the ice-lake boundary layer are indicated by arrows. b) Modelled temperatures at the ice-lake interface. The solid red line indicates the track along the cross sections shown in Figures 9b. 

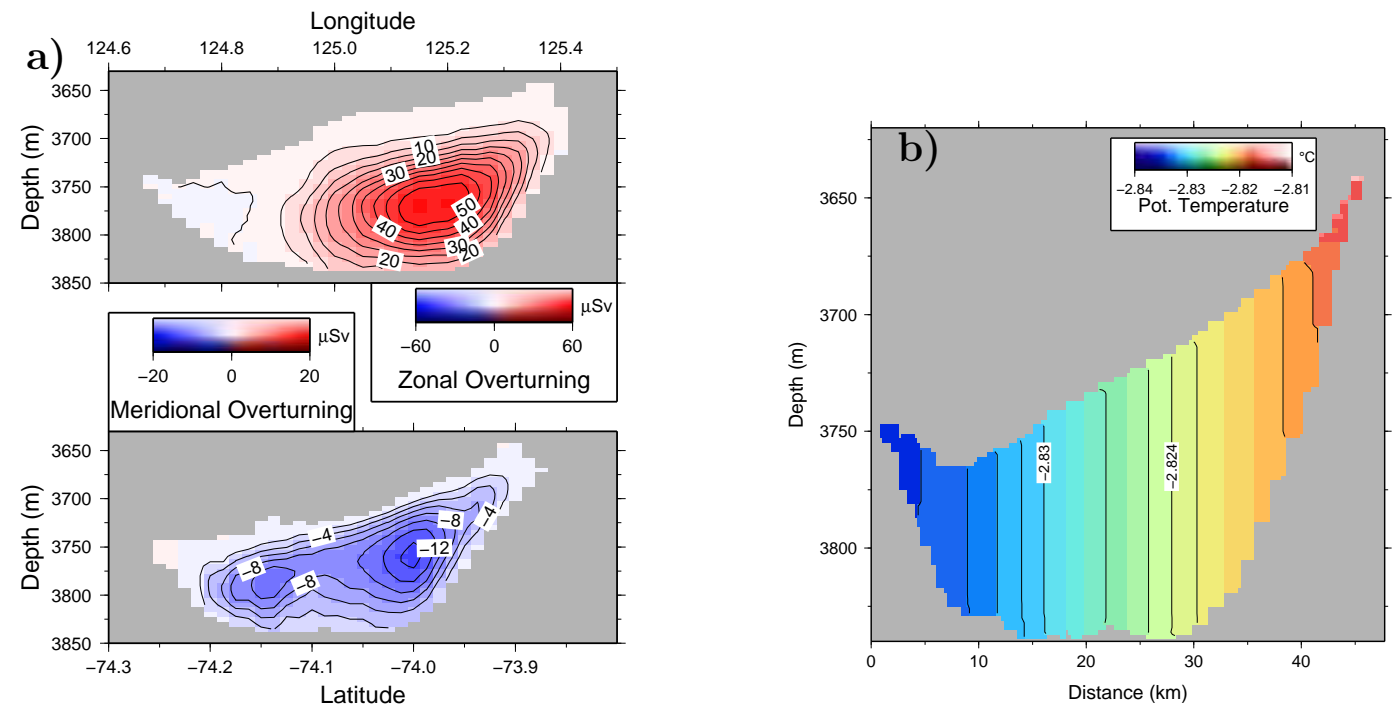

Fig. 9. a) Zonal and meridional overturning stream functions $\left(1 \mathrm{~Sv}=10 \mathrm{~m}^{3} / \mathrm{s}\right)$. b) South-north temperature cross section across Lake Concordia along the track indicated in Figure 6 and 8b.

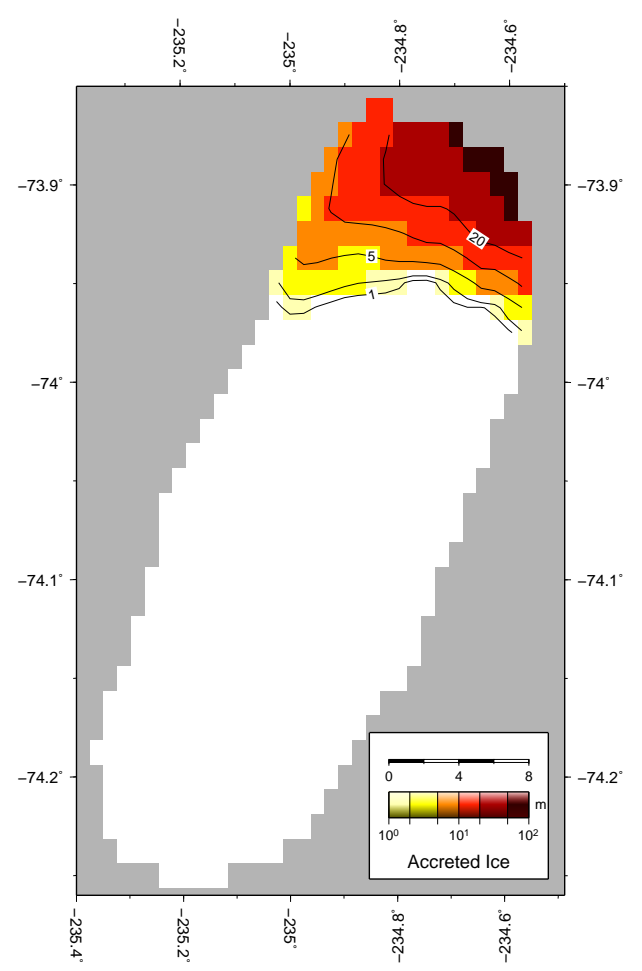

Fig. 10. Modelled accreted ice thickness (in meter) at the ice-lake interface The corresponding ice flow line direction is east-northeastward. The horizontal ice flow velocity is assumed to be $25 \mathrm{~cm} / \mathrm{a}$ (Tikku et al., 2005). 


\section{References}

Bell, R. E., Studinger, M., Tikku, A. A., Clarke, G. K. C., Gutner, M. M., Meertens, C., 2002. Origin and fate of Lake Vostok water frozen to the base of the East Antarctic ice sheet. Nature 416, 307-310.

Filina, I. Y., Blankenship, D. D., Thoma, M., Lukin, V. V., Masolov, V. N., Sen, M. K., 2008. New 3D bathymetry and sediment distribution in Lake Vostok: Implication for pre-glacial origin and numerical modeling of the internal processes within the lake. Earth Pla. Sci. Let. 276, 106-114, doi:10.1016/j.epsl.2008.09.012.

Kwok, R., Siegert, M. J., Carsey, F. D., 2000. Ice motion over Lake Vostok, Antarctica: constraints on inferences regarding the accreted ice. J. Glaciol. 46, 689-694.

Maule, C. F., Purucker, M. E., Olsen, N., Mosegaard, K., Jul. 2005. Heat Flux Anomalies in Antarctica Revealed by Satellite Magnetic Data. Science 309, 464-467, doi: 10.1126/science.1106888.

Thoma, M., Filina, I., Grosfeld, K., Mayer, C., 2009. Modelling flow and accreted ice in subglacial Lake Concordia, Antarctica. Earth Pla. Sci. Let. 286 (1-2), 278-284.

Thoma, M., Grosfeld, K., Mayer, C., Dec. 2007. Modelling mixing and circulation in subglacial Lake Vostok, Antarctica. Ocean Dynamics 57 (6), 531-540, doi: 10.1007/s10236-007-0110-9.

Thoma, M., Grosfeld, K., Mayer, C., 2008a. Modelling accreted ice in subglacial Lake Vostok, Antarctica. Geophys. Res. Lett. 35 (L11504), 1-6, doi:10.1029/2008GL033607.

Thoma, M., Mayer, C., Grosfeld, K., 2008b. Sensitivity of Lake Vostok's flow regime on environmental parameters. Earth Pla. Sci. Let. 269 (1-2), 242247, doi:10.1016/j.epsl.2008.02.023.

Tikku, A. A., Bell, R. E., Studinger, M., Clarke, G. K. C., 2004. Ice flow field over Lake Vostok, East Antarctica inferred by structure tracking. Earth Pla. Sci. Let. 227, 249-261, doi:10.1016/j.epsl.2004.09.021.

Tikku, A. A., Bell, R. E., Studinger, M., Clarke, G. K. C., Tabacco, I., Ferraccioli, F., 2005. Influx of meltwater to subglacial Lake Concordia, east Antarctica. J. Glaciol. 51 (172), 96-104.

Wendt, A., 2005. Untersuchungen zu gezeitenbedingten Höhenänderungen des subglazialen Lake Vostok, Antarktika. Berichte zur Polar und Meeresforschung 511 . 